\title{
Mechanism of grape seeds extract protection against paracetamol renal cortical damage in male Albino rats
}

\author{
Abdel-Hafez SMN ${ }^{1}$, Rifaai RA ${ }^{1}$, Abd Elzaher WY2 \\ Department of Histology, Faculty of Medicine, Minia University, Minia, Egypt. walaayehia22@ yahoo.com
}

\begin{abstract}
OBJECTIVE: The aim of the study was to assess the possible protective role of grape seeds extract (GSE) in ameliorating the toxic effects of paracetamol overdose on the rat renal cortical tissue.

BACKGROUND: Paracetamol is one of the widely used non-steroidal anti-inflammatory drugs (NSAIDs). Unfortunately, it was reported as the most common cause of toxic ingestion in the world. Grape seeds extract (GSE) is known to have a strong antioxidant and anti-inflammatory properties.

METHODS: The rats were divided into 4 groups; control group, GSE group, paracetamol group and GSE with paracetamol group. Kidney specimens were processed for biochemical, histological and immunohisto-chemical studies.

RESULTS: The study showed marked biological changes in the form of significant increase in serum urea and creatinine levels with significant decrease in renal superoxide dismutase with paracetamol group. Furthermore, Proximal (PCT) and distal convoluted tubules showed marked degeneration, dense nuclear staining, cytoplasmic vacuolization, and partial loss of the brush borders. Most tubules were dilated, irregular and were filled with hyaline casts. PCT and DCT showed less PAS reaction and more COX-2 and caspase expression if compared with the control and the GSE groups. Concomitant administration of grape seeds extract with paracetamol revealed a noticeable amelioration of these biochemical and histological changes. Proximal and distal convoluted tubules showed less PAS reaction and more $\mathrm{COX}_{2}$ and caspase expression if compared with the control and the GSE. Concomitant administration of GSE with paracetamol revealed a noticeable amelioration of these biochemical and histological changes. CONCLUSION: Grape seeds extract provided biochemical and histo-pathological improvement in paracetamol induced renal cortical toxicity. These findings revealed that this improvement was associated with a decrease in oxidative damage and apoptosis (Tab. 1, Fig. 7, Ref. 55). Text in PDF www.elis.sk. KEY WORDS: grape seeds extract, paracetamol, renal cortex and superoxide dismutase.
\end{abstract}

\section{Introduction}

Paracetamol is one of the most common NSAIDs widely used in the world. It acts as ananalgesic and antipyretic drug. Because of its wide availability paired with comparably high toxicity, (compared to aspirin and ibuprofen) there is a much higher potential for its toxicity (1). This drug is typically available as a singlecomponent formula or in combination with other simultaneously prescribed drugs. Although most medical practitioners generally consider it as the most save drug with fewer side effects than those of other analgesic and antipyretic medication, life-threatening hepatic toxicity is a clearly recognized adverse complication in patients with large dose ingestion (2). It was demonstrated that in few circumstances, persons died after taking less than the estimated minimum threshold toxic dose of paracetamol because of higher sensitivity to its toxic effects; hence, individual risk of toxicity fol-

${ }^{1}$ Department of Histology, Faculty of Medicine, Minia University, Minia, Egypt, and ${ }^{2}$ Department of Pharmacology, Faculty of Medicine, Minia University, Minia, Egypt

Address for correspondence: W.Y. Abd Elzaher, Department of Pharmacology, Faculty of Medicine, Minia University, 61111 Minia, Egypt. Phone: +201022381481 , Fax: +20862093070 lowing paracetamol toxicity was difficult to assess (3). Although nephrotoxicity is less common than hepato-toxicity in paracetamol overdose, renal tubular degeneration and acute renal failure can occur even in the absence of liver damage (4). Renal insufficiency occurs in approximately $1-2 \%$ of patients with paracetamol overdose (5) and can even lead to death in humans and experimental animals (6). Renal toxicity in paracetamol poisoning has been attributed to cytochrome P-450, although other mechanisms have been elucidated, including the role of prostaglandin (7).

It has been reported that oxidative stress induced by free oxygen radicals plays a significant role in paracetamol induced nephrotoxicity (8). Therefore, drugs or plant products having anti-oxidant properties might have the potential to prevent paracetamol induced nephrotoxicity (9). It is known that GSE has anti-oxidant effect that is approximately 50 times greater than that of vitamin $\mathrm{E}$ and vitamin C (10). Moreover, cell culture studies have reported its anti-carcinogenic effect, and its anti-apoptotic effect (11). In addition to the anti-oxidant and free radical scavenging properties, GSE also possess several other effects such as anti-inflammatory, vasodilatory, and inducible NOS inhibiting effect (12).

The aim of this study was to evaluate the possible protective effect of GSE on the biochemical, histopathological and immunohisto-chemical alterations in the rat renal cortex induced by 
paracetamol toxicity and also to study the possible mechanisms through which GSE produces its protective effect.

\section{Material and methods}

\section{Animals}

Twenty four male albino rats at the age of 7-10 weeks, weighing 190-210 grams were obtained from the National Research Center, Cairo, Egypt. Animals were housed in properly ventilated cages at room temperature $\left(25 \pm 2{ }^{\circ} \mathrm{C}\right), 45 \pm 5 \%$ humidity, and 12-h light/dark cycles and were allowed free access to standard rodent chow and water. Animals and their care were conducted according to the Research Advisory Ethical Committee of Faculty of Medicine, Minia University, Egypt. After 1 week of acclimatization, the rats were divided randomly into four groups of 6 animals each.

\section{Chemicals}

Paracetamol was purchased from Sigma Chemical (St. Louis, MO) and GSE was obtained from GNC standard commercial suppliers in Jeddah Saudi Arabia. Rabbit polyclonalCOX ${ }_{2}$ anti-
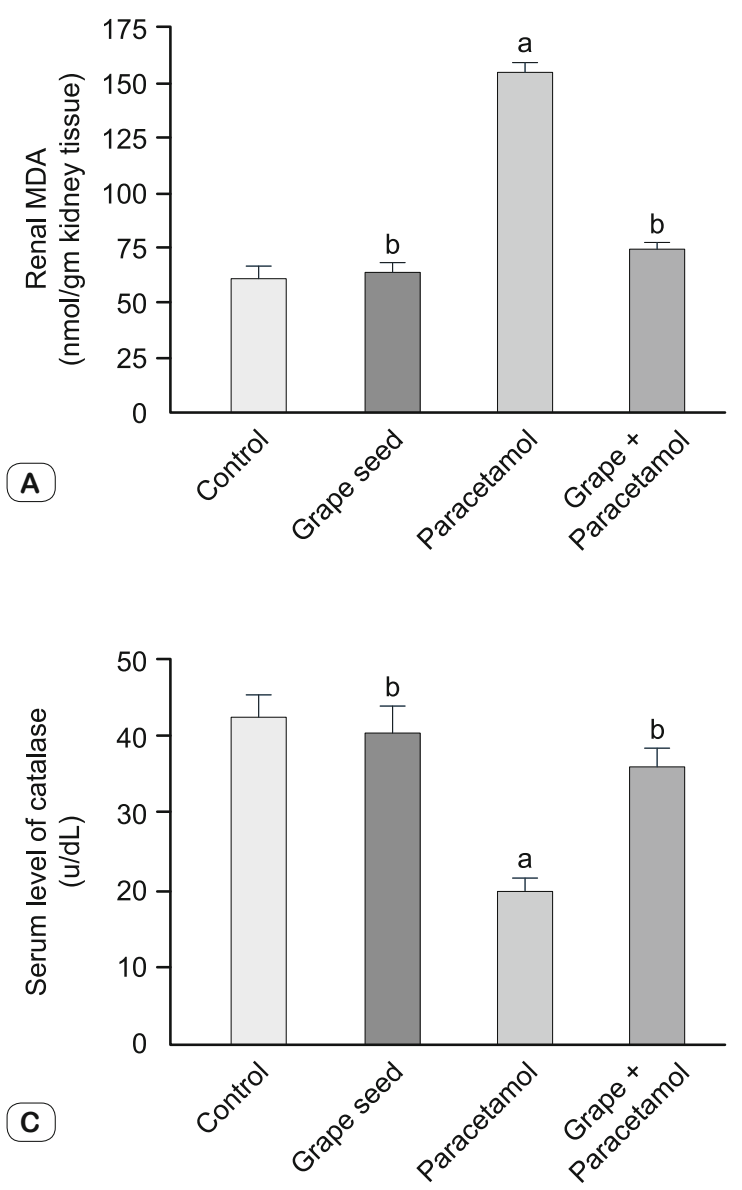

body (Abcam, USA), Rabbit Polyclonal caspase 3 antibody (Lab Vision, UK), biotinylated goat anti-rabbit secondary antibody (Transduction Laboratories, USA), kits for creatinine and urea (Diamond diagnostics, Egypt), alkaline phosphatase (BioMed, Egypt), reduced glutathione (GSH), catalase and superoxide dismutase (SOD) (Biodiagnostic, Egypt) were purchased. All other chemicals were of analytical grade and were obtained from commercial sources.

\section{Experimental design}

Animals were randomly divided into four groups as follows:

Control group (group I): It consists of 6 rats which received $5 \mathrm{ml}$ saline orally by gastric tube for 14 days.

Grape seeds extract (group II): It consists of 6 rats which received $250 \mathrm{mg} / \mathrm{kg}$ /day grape seeds extract orally for 14 days by gastric tube. The dose of GSE was chosen to be effective with no adverse effects (13). Paracetamol group (group III): It consists of 6 rats in which rats received normal saline for 14 days followed by single oral dose of paracetamol on the 15th day at a dose of $2 \mathrm{gm} /$ $\mathrm{kg}$ by gastric tube. This dose regimen of paracetamol was previously reported to induce renal damage in rats (14).
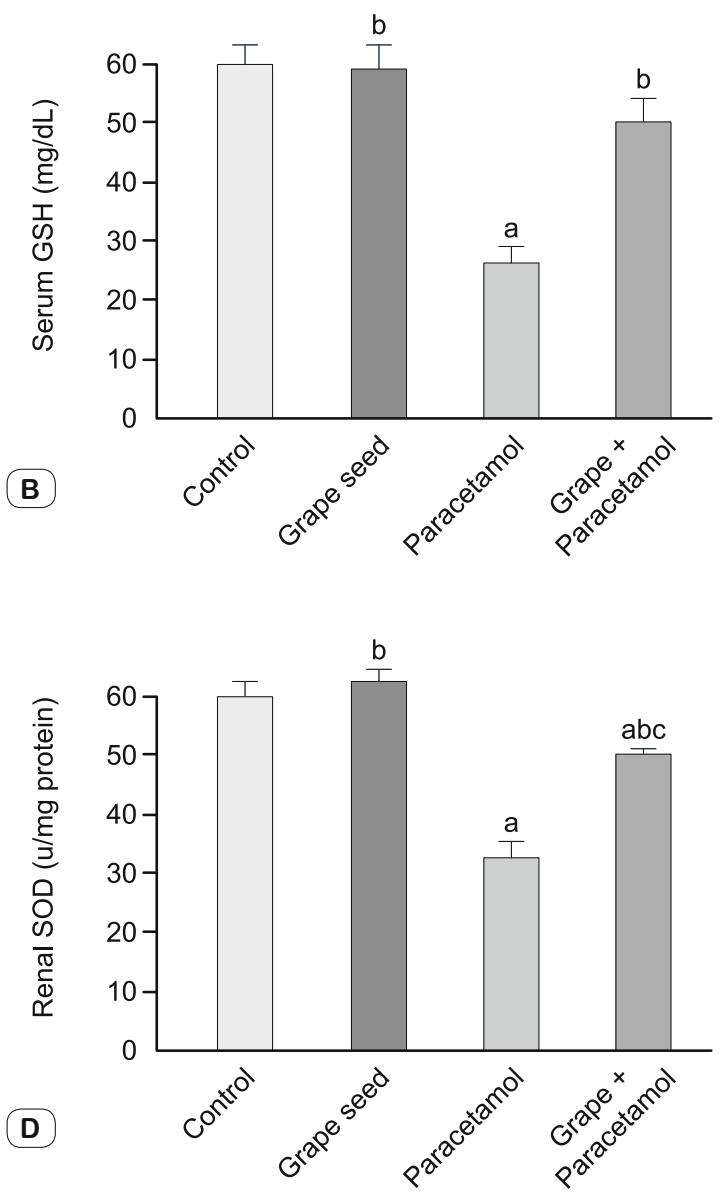

Fig. 1. Effect of GSE on renal MDA (A), serum GSH (B), serum catalase (C) and renal SOD (D) in paracetamol-iduced nephrotoxicity in rats: Results represent the mean \pm SE $(n=6)$. a significant $(p<0.05)$ difference from control group, ${ }^{b}$ significant $(p<0.05)$ difference from paracetamol treated group and ${ }^{\mathrm{c}}$ significant $(\mathrm{p}<0.05)$ difference from grape seeds extract treated group. 
Paracetamol and grape seeds group (group IV): It consisted of 6 rats that received a daily oral dose of GSE of $250 \mathrm{mg} / \mathrm{kg} /$ day for 14 days by gastric tube followed by single oral dose of paracetamol $2 \mathrm{gm} / \mathrm{kg} /$ day by gastric tube at the 15 th day.

Treatments were performed between 9.00 and 10.00 am to minimize possible diurnal effects. At $48 \mathrm{~h}$ after paracetamol ingestion for all groups, animals were anesthetized with ether and sacrificed. Blood samples were collected from each rat for biochemical analysis and tissue samples were also collected for tissue homogenates preparation, histopathological and immunohistochemical studies.

\section{Biochemical analysis}

Blood samples were centrifuged (centrifuge Jantezki, T30, Germany), at $5000 \mathrm{rpm}$ for 10 minutes for serum collection. Sera were separated and kept in refrigerator at $-80{ }^{\circ} \mathrm{C}$ until assessment of various parameters.

Serum levels of creatinine, urea, alkaline phosphatase, catalase, GSH and renal DOS activities were detected according to the manufacturers' guidelines using commercially available kits.

Renal malondialdehyde (MDA), an index of lipid peroxidation, was determined by using 1, 1, 3, 3-tetramethoxypropane as standard (15).

\section{Preparation of Tissue Homogenates}

Specimens from kidney were weighed and homogenized separately in potassium phosphate buffer $10 \mathrm{mM} \mathrm{pH}$ (7.4). The ratio of tissue weight to homogenization buffer was 1:5. The homogenates were centrifuged at $5000 \mathrm{rpm}$ for $10 \mathrm{~min}$ at $4^{\circ} \mathrm{C}$. The resulting supernatant was kept at $-80^{\circ} \mathrm{c}$ until assessment of MDA and SOD levels.

\section{Histopathology and immunohistochemical study}

Fresh small pieces were obtained from each animal and fixed in $10 \%$ neutral-buffered formalin, dehydrated in a graded alco- hol series, cleared with xylene and embedded in paraffin wax. The sections ( $5 \mu \mathrm{m}$ thick) were stained with Hematoxylin and Eosin stain (H\&E) for studying the general histological structure and with Periodic acid Schiff method (PAS) for demonstration of neutral muco-substances (16). Additional slides were preceded for immunohistochemical study. Immunohistochemical staining was performed using polyclonal rabbit antibodies $\left(\mathrm{COX}_{2}\right.$ andcaspase 3). Immunohistochemistry for anti- $\mathrm{COX}_{2}$ and anti-active caspase 3 was performed on formalin-fixed, paraffin-embedded tissue. Sections were de-paraffinized with xylene, dehydrated in a graded series of alcohol solutions and then washed in $0.1 \mathrm{M}$ phosphate buffer saline (PBS). Endogenous peroxidases were quenched by using $3 \% \mathrm{H}_{2} \mathrm{O}_{2}$ for $15 \mathrm{~min}$ in methanol (Peroxidase blocking solution) followed by washing in tris buffer saline (TBS). Non-specific binding of IgG was blocked by adding normal goat serum, diluted $1: 50$ in $0.1 \%$ bovine serum albumin with TBS for $30 \mathrm{~min}$. Diluted primary antibodies for anti-COX (1:2000) and anti-caspase 3 (ready to use) were applied on the slides overnight at room temperature. Sections then were washed perfectly 3 times each for 5 minutes in buffer and incubated for further $30 \mathrm{~min}$. with biotinylated goat anti-rabbit secondary antibodies diluted $1: 1000$, followed by several washing. Following further $30 \mathrm{~min}$. incubation with Vectastain $\mathrm{ABC}$ kits (Avidin, Biotinylated horse radish peroxidase Complex) and washing for 10 minutes, the substrate, diaminobenzidine tetra hydrochloride (DAB) in distilled water was applied for 5-10 min. The slides were lightly counterstained by using hematoxylin to gain a clear morphological identification of cells, and dehydrated by passing through ascending concentrations of ethanol then cleared with xylene. Cover slip using mounting media is put. This substrate gives a clear brown stain at the immune-reactive sites (17). The positive control for anti-COX2 antibody was lung carcinoma while positive control for the anti-caspase 3 antibody was human tonsil. For negative control slides, the same steps, but without the 1ry antibody (not included).
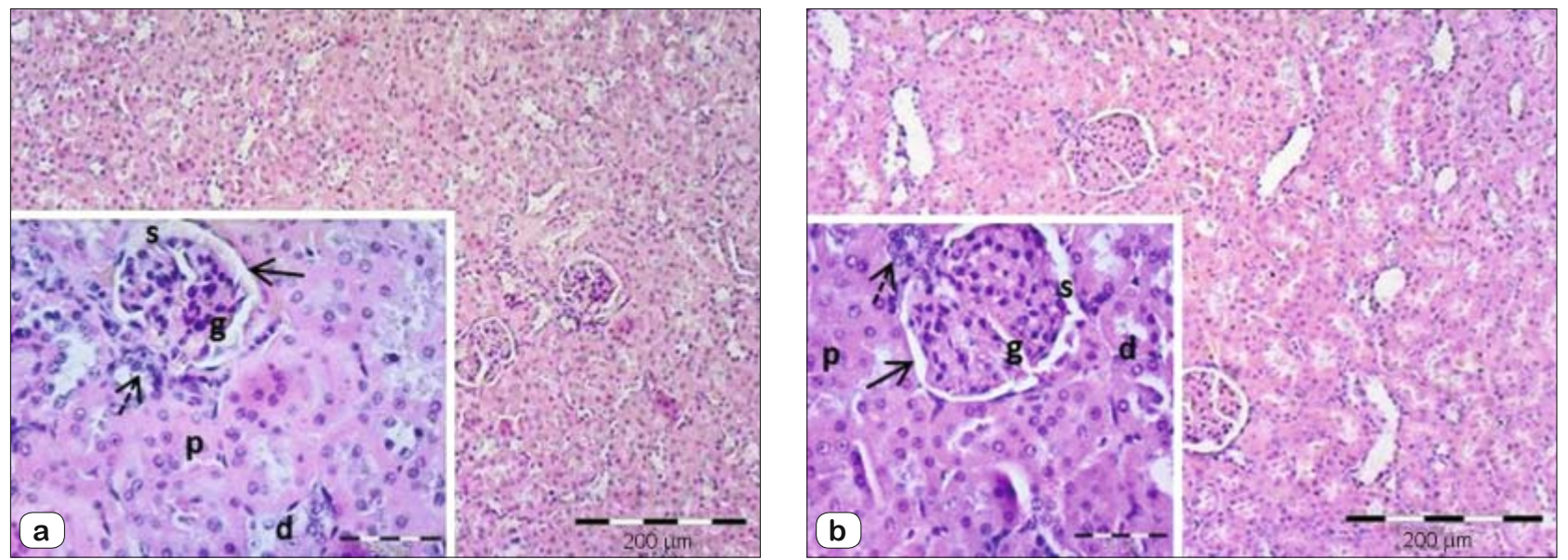

Fig. 2. A photomicrograph of renal cortex of group I (a) and group II ( b ) stained by H\&E showing normal organization of the renal cortex. The insets showing the glomerular capillary tufts (g), the parietal layer of Bowman's capsule (arrow), and Bowman's space (s). PCTs (p) have a narrow lumen and a highly acidophilic cytoplasm. DCTs (d) have a wider lumen and less acidophilic cytoplasm. Notice the macula densa cells (dash arrow) of the DCTs. (Magnification x100 and insets x400). 
Tab. 1. Effect of grape seed extract on serum creatinine, urea and alkaline phosphatase in paracetamol-induced nephrotoxicity in rats.

\begin{tabular}{lcccc}
\hline Groups & Control group & GSE- treated group & Paracetamol treated group & GSE+paracetamol treated group \\
\hline Urea (mg/dl) & $21.67 \pm 1.45$ & $28.83 \pm 3.75^{\mathrm{b}}$ & $88.50 \pm 5.03^{\mathrm{a}}$ & $45.67 \pm 2.11^{\mathrm{ab}}$ \\
Serum creatinine (mg/dl) & $0.77 \pm 0.12$ & $0.79 \pm 0.09^{\mathrm{b}}$ & $3.58 \pm 0.30^{\mathrm{a}}$ & $1.2 \pm 0.15^{\mathrm{b}}$ \\
Serum alkaline phosphatase (U/L) & $101.67 \pm 6.28$ & $106.6 \pm 5.85^{\mathrm{b}}$ & $157.92 \pm 3.98^{\mathrm{a}}$ & $119.51 \pm 4.4^{\mathrm{b}}$ \\
\hline
\end{tabular}

Results represent the mean \pm SE $(n=6),{ }^{a}$ Significant $(p<0.05)$ difference from control group, ${ }^{b}$ significant $(\mathrm{p}<0.05)$ difference from paracetamol treated group and ${ }^{\mathrm{c}}$ significant $(\mathrm{p}<0.05)$ difference from grape seeds extract treated group

\section{Photography}

An Olympus (U.TV0.5XC-3) light microscopy was used. Slides were photographed using an Olympus digital camera. Images were processed using Adobe Photoshop.

The mean area fraction of anti-COX $\mathrm{CON}_{2}$ and anti-caspase 3 expression wasquantified in 6 fields for each group using image J 22 program.

\section{Statistical analysis}

Results were expressed as means \pm standard error of mean (SEM). One-way analysis of variance (ANOVA) followed by the Tukey-Kramar post analysis test were used to analyze the results for statistically significant difference P value was used identify the effect of the treatment on the biochemical and immunological markers, and comparison between treatment groups respectively. Less than $0.05 \mathrm{p}$ values were considered significant. Graph Pad Prism was used for statistical calculations (version 3.02 for Windows, Graph pad Software, San Diego California USA, and www.graphpad.com).

\section{Results}

\section{Biochemical study}

Serum creatinine, urea and alkaline phosphatase were significantly increased in the paracetamol treated group as compared to the control group. GSE solely or in combination with paracetamol caused a significant decrease in serum creatinine, urea and alkaline phosphatase as compared to the paracetamol treated group (table 1).

Furthermore, Paracetamol caused significant increase in renal MDA level with significant decrease in renal SOD, serum GSH and catalase as compared to the control group. On the other hand, co- administration of GSEand paracetamolsignificantly improved these parameters when compared with paracetamoltreated group;it caused significant decrease in renal MDA level with significant increase in renal SOD, serum GSH and catalase as compared to the paracetamol group (Fig. 1).
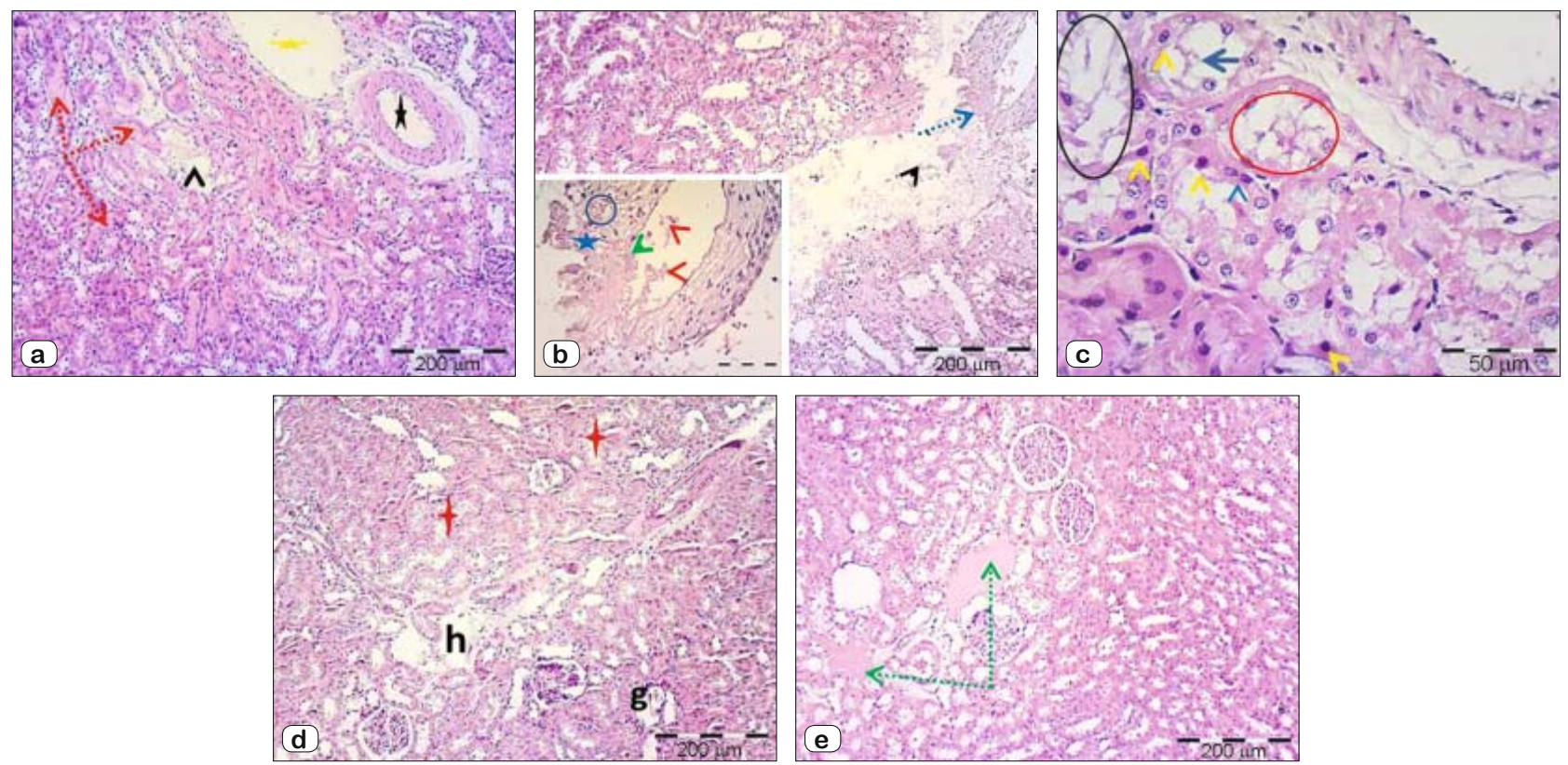

Fig. 3. A photomicrograph of renal cortex of group III stained by H\&E showing a) Vascular dilatation-(black \&yellow stars) and widening of inter-tubular space (black arrow head). Most tubules are cystic dilated and irregular in shape with hyaline casts in their lumen (dash red arrows). b) Rupture artery (dash blue arrow), widening inter-tubular space (black arrow head). The inset showing Intra-luminal debris (red arrow heads), discontinuity endothelial layer (green arrow head) and muscular layer (blue star) and extravasation of RBCs (black circle). c) Higher magnification showing tubular cells with small rounded eccentric nucleus and strongly acidophilic cytoplasm (yellow arrow heads). Some tubular cells appear with flatted lined nuclei (blue arrow head). Notice the vacuolization of PCT (red circle) and DCT (black circle) cells and the intra luminal cellular debris (blue arrow) d) Distorted renal glomerulus with widening of Bowmann's spaces (g). Notice the distorted renal tubules (red stars) and inter-tubular hemorrhage (h). e) The amyloidal substance (dash green arrows). (Magnification x100 and insets, c) x400). 

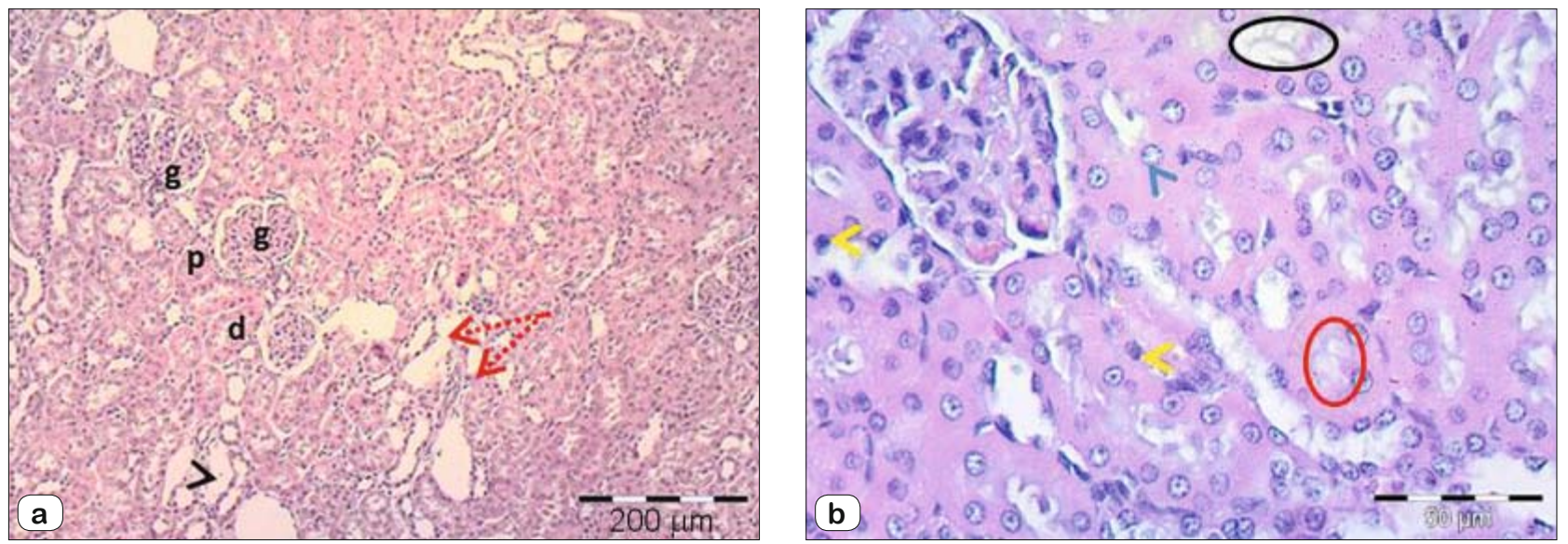

Fig. 4. A photomicrograph of renal cortex of group IV stained by H\&E showing. a) Most of the renal corpuscles (g), PCT (p) and DCT (d) restore their normal architecture. No visible intra-luminal cast or amyloidal substance. Notice area of wide inter-tubular space (black arrow head) and some dilated tubules (dash red arrows). No visible hemorrhage or edematous areas are noticed. b) Most PCTs and DCTs retained their apparently normal lining epithelial (blue arrow head). Few cells appear with small dark nucleus (yellow arrow head). Notice the Less vacuolization of PCT (red circle), DCT (black circle) and some intra-tubular debris (blue arrow). Magnification a) x100 and b) x400)
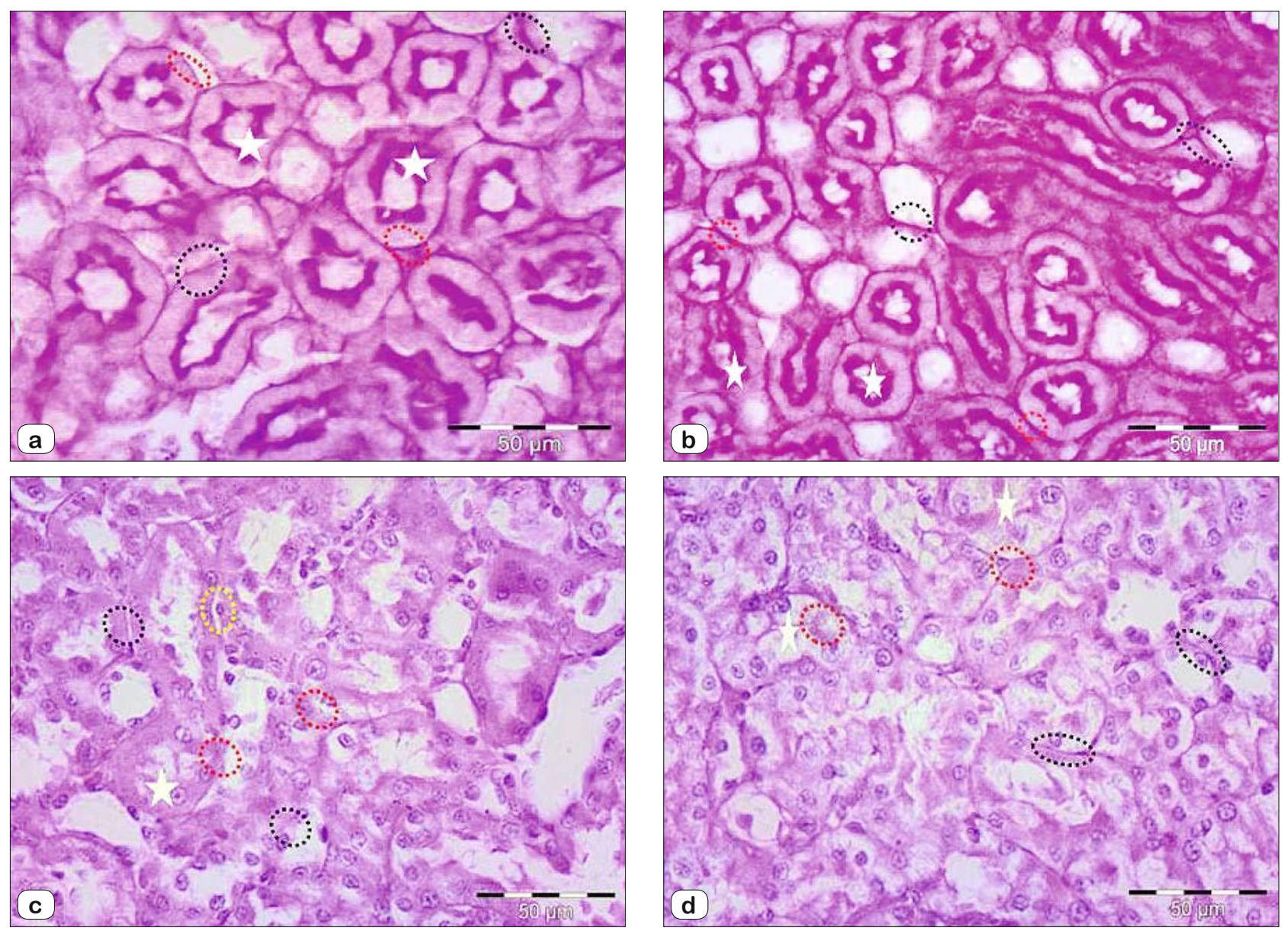

Fig. 5. A photomicrograph of renal cortex stained with PAS. a) \&b are group I \&II showing the same positive PAS reaction in the BMs of PCT (dash red circles) and DCT (dash black circles) cells. Notice the staining of brush borders (stars) of the PCT cells. C) Group III showing that most PCTs (dash red circles) and DCTs (dash black circles) showing interruption of the BMs at many sites. The brush borders of PCT cells show less PAS reaction (star). Notice the detached BM in some tubules (dash yellow circle). d) Group IV showing that most PCT (dash red circles) and DCT (dash black circles) cells retained their apparent normal BMs. Notice the reappearance of brush border in few PCTs (stars). (Magnification x400) 

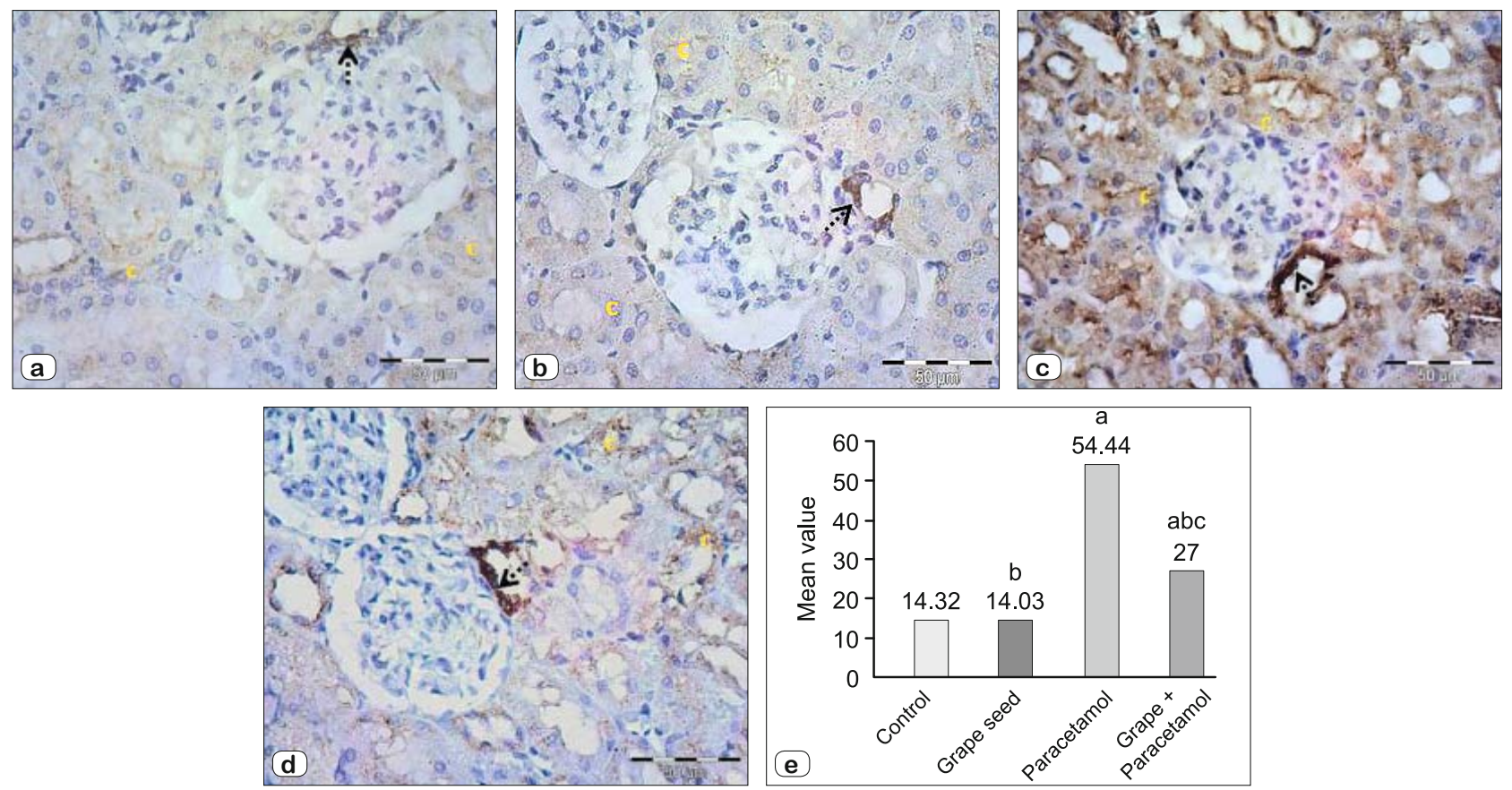

Fig. 6. A photomicrograph of renal cortex immuno-stained for $\mathrm{COX}_{2}$. a) and b) Group I \& II respectively showing the same cytoplasmic expression in macula densa cells (dash black arrow). Notice the faint expression in the renal tubular cells (c). C) Group III showing deeply stained cytoplasmic expression in macula densa cells (dash black arrow). Notice that most renal tubular cells (c) showing deeply $\mathrm{COX}_{2}$ cytoplasmic expression. d) Group IV showing strong cytoplasmic expression in macula densa cells (dash black arrow) but with less observable cytoplasmic

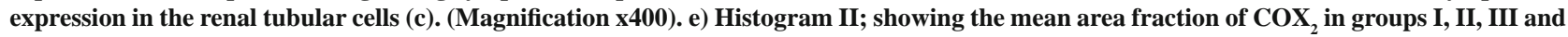
IV. Results represent the mean \pm SE $(n=6) .{ }^{a}$ significant $(p<0.05)$ difference from group ${ }^{\text {, }}{ }^{b}$ significant $(p<0.05)$ difference from group III group and ${ }^{\mathrm{c}}$ significant $(\mathrm{p}<\mathbf{0 . 0 5 )}$ difference from group II treated group.

\section{Histological study}

Histological study renal cortex using hematoxylin and eosin

Group I and II had the same histological structure. The renal cortex contained numerous renal corpuscles, proximal (PCT) and distal (DCT) convoluted tubules. The renal corpuscles showed tufts of capillaries, the glomeruli which surrounded by the Bowman's capsules. The Bowman's spaces were shown between the glomeruli and Bowman's capsules. Both parietal and visceral layers of each Bowman's capsule were distinct. The parietal layers of Bowman's capsules were lined by simple squamous epithelium. The glomeruli were shown to be in intimate contact with the visceral layers of Bowman's capsules. The PCTs were lined with thick large cubical epithelium with acidophilic cytoplasm. It had rounded vesicular nuclei. The DCTs lined with considerably lower cubical epithelium surrounding relatively by larger regular distinct lumens with less acidophilic cytoplasm than the cells of the PCTs. It had also rounded vesicular nuclei. The macula densa were clearly identified where their cells were narrow, pale, and tall collectively, viewed with the light microscope as a dense spots (Figs 2a and 2b).

The renal cortex of group III revealed marked renal cortical distortion with vascular dilatation (Fig. 3a). In some sections, damage of arterial wall with extravasation of blood element and discontinuous endothelial and muscular layer were noticed (Fig. $3 b)$. The renal tubules were widely spaced and filled with amor- phous hyaline casts (Fig. 3a). Regarding tubular cells, some PCTs and DCTs showed small eccentric nuclei with strong acidophilic cytoplasm, others showed cytoplasmic vacuolization. Evident of intraluminal cellular debris was also clear (Fig. 3c). Renal glomeruli became distorted and shrunken with apparent widening of the Bowman's spaces (Fig. 3d). Many section showed multiple areas of amyloid substance deposition (Fig. 3e).

Sections of the renal cortex of group IV showed improvement of renal cortical morphology which approached the corresponding normal renal cortical sections. No visible hemorrhage, intraluminal hyaline casts or amyloidal substances were noticed. Most of the glomeruli, PCTs and DCTs appeared to restore their normal structure and retained their apparently normal lining epithelium (Fig. 4a). Less intra-luminal debris and tubular cell vacuolization were also noticed. Only few cells appeared with dark nuclei (Fig. $4 b)$. Still scattered areas showed wide inter-tubular space and dilated cortical tubules (Fig. 4a).

Histological study of renal cortex using periodic acid-schiff (PAS)

In group I\& II, the renal cortical tissues showed positive PAS reactions in the basement membranes (BMs) of PCT and DCT cells. It was also observed in the intact apical brush borders of PCT cells (Figs 5a and 5b). In group III, there was less PAS positive staining in the BMs of PCT and DCT cells in comparison with previous groups as most PCTs and DCTs showed interrup- 

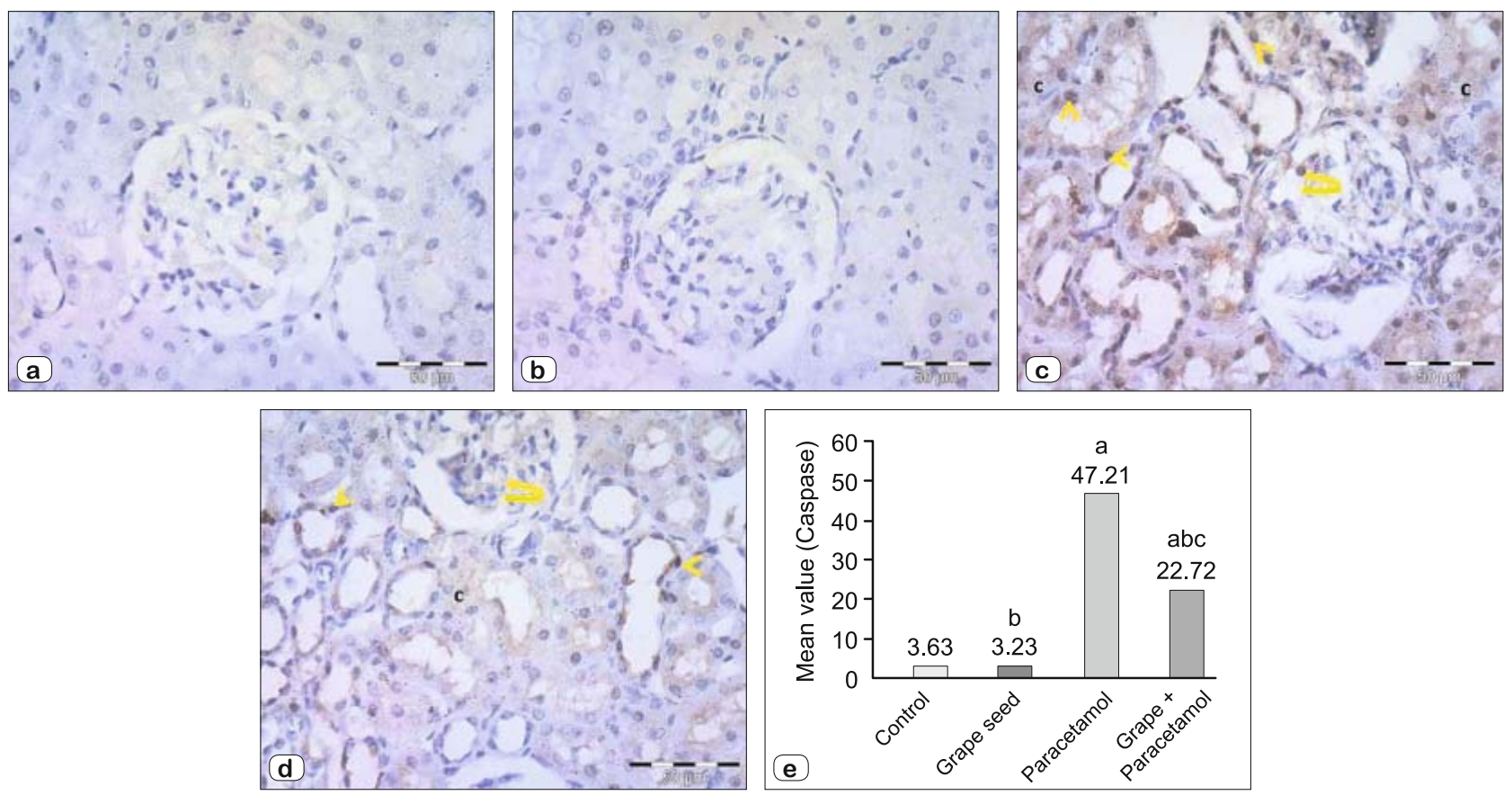

Fig. 7. A photomicrograph of renal cortex immuno-stained for caspase 3. a) \& b Group I and Group IIrespectively showing negative immuno-reactivity. c) Group III showing high nuclear (yellow arrow heads) and cytoplasmic expression (C) in the renal tubular cells). Positive expression is evident in the glomeruli (curved arrow). d) Group IV showing apparent decrease in nuclear (yellow arrow heads) and cytoplasmic (C) expression in most renal tubules. Few glomerular cells $(\underline{C})$ showing weak cytoplasmic expression. (Magnification x400). e) Histogram II; showing the mean area fraction of caspase 3 in groups I, II, III and IV. Results represent the mean \pm SE $(n=6)$. ${ }^{\text {a }}$ significant $(p<0.05)$ difference from group I, ${ }^{b}$ significant $(p<0.05)$ difference from group III group and ${ }^{\mathrm{c}}$ significant $(p<0.05)$ difference from group II treated group.

tion of their BMs at many sites. The brush borders of PCT cells showed less PAS reaction. Some sections of the renal cortex of this group showed detachment of many tubular epithelial cells from their BMs (Fig. 5c). In group IV; nearly all PCTs and DCTs cells retained their apparent normal basement membrane PAS staining. Reappearance of the brush borders in some PCTs was noticed (Fig. 5d).

\section{Immunohistochemical study}

Immunohistochemical study of the rat renal cortical tissues using anti-COX antibody

For immunohistochemical study $\mathrm{COX}_{2}$ was used as a marker of inflammation. $\mathrm{COX}_{2}$ expression appeared as cytoplasmic brown staining. Group I and II showed cytoplasmic expression in few macula densa cells of DCTs, while the cells of the renal tubular cells displayed faint $\mathrm{COX}_{2}$ immuno-reactivity (Figs 6a and 6b). In group III; dense expression in the macula densa cells of DCTs was observed. Most of the cortical renal tubules showed also dense positive expression. The expression was mainly cytoplasmic (Fig. 6c). In group IV, most of the renal cortical tubules showed faint cytoplasmic expression except in the macula densa cells of distal tubules that showed dense cytoplasmic expression (Fig. 6d).

The mean area fraction of $\mathrm{COX}_{2}$ for all groups is presented in Histogram I; there was a significant increase in group III compared to group I, while there was significant decrease in group IV when compared to group III (Fig. 6e).
Immunohistochemical study of the rat renal cortical tissues using anti-caspase 3 antibody

As a marker of apoptosis, immune histochemical staining for anti-caspase 3 was used. Caspase 3 expression appeared as brown staining either nuclear or cytoplasmic. Immunohistochemical staining of group I and II revealed a negative caspase 3 activity (Figs $7 \mathrm{a}$ and $7 \mathrm{~b}$ ), while in group III caspase 3 is highly expressed in the cytoplasm and nuclei of the cells lining renal tubules. Also positive nuclear expression was noticed in the glomeruli (Fig. 7c). Concomitant administration of GSE with paracetamol apparently reduced caspase 3 expression in both tubules and glomeruli (Fig. 7d).

The mean area fraction of caspase 3 for all groups is presented in Histogram II; there was a significant increase in group III compared to group I, while there was significant decrease in group IV when compared to group III (Fig. 7e).

\section{Discussion}

Although the hepato-toxic mechanism of paracetamol toxicity is well described, there is a little evidence of the nephrotoxic mechanism of paracetamol. Based on the clinical and animal studies, some of the potential mechanisms of nephrotoxicity are N-deacetylase enzymes, the cytochrome P-450 pathway and prostaglandin synthesis (18). The selective renal accumulation of NSAIDs including paracetamol both in animal and human is thought to result in a chain of biochemical reactions which lead to acute or chronic 


\section{3-242}

nephropathies (19). With overdose of paracetamol, the reactive derivative of paracetamol occurred by the P-450-dependent metabolism, N-acetyl-P-benzoquinone imine could not be detoxified by GSH and depleted GSH levels lead to liver necrosis and liver failure (20). Loss of glutathione with an increased formation of reactive oxygen species and increased oxidative stress are essential events of the toxicity mechanism. Toxic dose of paracetamol is due to some metabolic disorders such as serum electrolytes, alkaline phosphatase, creatinine and urea de-arrangements. Serum creatinine and urea are considered nephrotoxicity markers, but serum urea concentration is more reliable (21).

Administration of toxic single dose of paracetamol showed significant increase in serum level of urea, alkaline phosphatase enzyme and creatinine as compared to control \& GSE group. These results were in consistence with the experimental findings (22) and similar to that clinically reported before (23). Also, elevation of serum alkaline phosphatase induced by toxic dose of paracetamol was considered as specific marker of renal inflammation (24).

Studies of Karadeniz et al (25) and Ajami et al (26) demonstrated increase in the levels of creatinine and urea due to strong correlation between nephrotoxicity and oxidative stress. The elevated $\mathrm{H}_{2} \mathrm{O}_{2}$ and $\mathrm{O}^{2-}$ production alters the filtration surface area and modifies the filtration coefficient; both factors could decrease the glomerular filtration leading to accumulation of urea and creatinine in the blood.

Malondialdehyde can be stimulated by free radicals (27). Increased level of MDA reflected tissue damage (28), SOD and GSH are key anti-oxidant defense system enzymes to detoxify reactive molecules or repair the resulting damage in the cell (29).

Paracetamol in acute single toxic dose elicited significant increase in the level of renal MDA with significant decrease in renal SOD, serum GSH and serum catalase. These results were supported by a previous (22) that observed a significant decrease in the levels of SOD and GSH with significant increase in MDA after acute paracetamol overdose administration. Significant decrease in levels of SOD and catalase after acute paracetamol overdose administration to rats is based on the observation that paracetamol overdose enhances lipid peroxidation or inactivates the anti-oxidative enzymes. (30). In renal injury, superoxide radicals are generated at the site of damage and modulate catalase and SOD, resulting in the loss of activity and accumulation of superoxide radical, which damages kidney. Catalase and SOD are the most important enzymes which affect the oxygen metabolism (31).

Current evidence suggests that intra-cellular GSH played an important role in detoxication of paracetamol with decrease of its toxicity in the liver and kidney (32). The reactive oxygen species appeared as an early event before intracellular GSH depletion and cell damage in paracetamol toxicity (33).

These biochemical alterations were corroborated by the histological findings. This study showed various morphological changes in the renal cortex after paracetamol ingestion, in the form of; interstitial hemorrhages, glomerular and tubular cell degeneration and renal inflammation. These findings were supported by Trumper et al (34) who reported that paracetamol overdose produced acute tubular necrosis in male rats. These results were also in compli- ance with Ganga et al (35) who described the renal histological alterations following overdose administration of paracetamol.

Regarding the dilated tubules observed in this study, Sanchez et al (36) explained that dilatation might be a compensatory mechanism after loss of renal excretory function of nephrons by tubular degeneration.

Examination of renal cortical tubules of paracetamol treated group showed amorphous protein casts in their dilated lumen. This finding was reinforced by the recorded result which mention that there were multiple hyaline casts and epithelial cells in urinary sediments after single intra-peritoneal dose of $1 \mathrm{gm} / \mathrm{kg}$ paracetamol (37). The presence of these amorphous substances in the renal tubular lumens might be an indication of glomerulonephritis and or incapability of these tubules to counter the accumulated residues resulting from metabolic and structural alterations (38). The necrotic epithelial cells enhanced the matrix for intraluminal cast formation which eventually resulted in tubular obstruction (39).

Extravasation of RBCs and dilated blood vessels were also encountered in the interstitium of the renal cortex. Congested blood vessels and extravasation of RBCs were a clear finding after acute paracetamol exposure (22). Extravasation of RBCs could be explained before; as a result of increase in vascular permeability by affecting the communicating units between endothelium of the venues and capillaries; hemorrhage occurred (40).

Loss of integrity and distortion of the brush borders of PCT observed in this work, was agreement with Mohamed et al (41) who added that paracetamol caused a reduction in alkaline phosphatase activity in the brush border membrane of PCTs and an increase in the urinary excretion of the brush border membrane enzyme $\gamma$-glutamyl trans-peptidase so it was observed that these brush borders seemed to be very sensitive to this drug.

Paracetamol caused dense $\mathrm{COX}_{2}$ cytoplasmic expression in the macula densa cells of DCTs and most cortical tubules. This was in line with De Broe et al (42) who suggested increased reno-cortical $\mathrm{COX}_{2}$ expression and prostaglandin $\mathrm{E}_{2}$ formation after high dose of paracetamol ingestion. It was also supported by Damera et al (24) who added that paracetamol induced sever inflammation in renal cortical tissue.

Features of apoptosis were clearly observed in tubular cells. It was in the form of dark strong acidophilic cytoplasm with dense eccentric nuclei. Caspase 3 was highly expressed in the cytoplasm and nuclei lining renal tubules and in the glomerular cells. The apoptosis noticed in this study was explained by Corina et al (43) who found that paracetamol induced apoptosis of cultured murine tubular epithelial cells through a caspase-mediated mechanism that involves caspase- 3 and caspase-9. Caspase- 12 has been reported to cleave caspase- 9 in vitro in the absence of cytochrome C. This raises the possibility that caspase- 12 is the apical caspase in paracetamol-induced apoptosis in tubular epithelial cells. Fouad et al (44) found also severe apoptotic bodies after a single oral dose of $2.5 \mathrm{~g} / \mathrm{kg}$ of paracetamol.

Administration of GSE significantly reduced the toxic effects of paracetamol on the kidneys. The nephroprotective properties of GSE may be due to its positive effects on the anti-oxidant system (45) and its anti-inflammatory effect (46). GSE showed a broad 
spectrum of pharmacological, therapeutic and medical properties $(47,48)$.

The present work indicated that pretreatment with GSE showed significant amelioration in the lipid peroxidation caused by paracetamol in the form of decreased MDA level, accompanied by enhanced activities of catalase and SOD and increased GSH content, also it significantly improved the elevation in serum level of urea, creatinine and alkaline phosphatase. These results were supported by other findings (49) which demonstrated that GSE treatment significantly improved anti-oxidant status and decreased MDA in the ethylene glycol-induced nephrotoxic mice. Also they were in agreement with previous studies (50) which demonstrated that treatment with GSE improved oxidative stress and the elevation of TNF- $\alpha$ production after paracetamol toxicity in rat liver.

In the current study there was a considerable amelioration in the morphological changes of renal cortical tissue when GSE was given with paracetamol. These finding was in line with other investigators (51)who suggested that GSE provided histopathological amelioration after contrast induced nephropathy. It was also in agreement with other work which suggested that GSE has a strong reactive oxygen species scavenging and anti-oxidant features (52).

Significant decrease in inflammation was noticed by concomitant administration of GSE with paracetamol and it was clearly noticed by immunohistochemistry $\mathrm{COX}_{2}$ staining. This finding was in line with Terra et al (53) who suggested that GSE reduced pro-inflammatory cytokines so it has an anti-inflammatory effect.

Furthermore, the nephroprotective property of the GSE was confirmed by significant decrease of in apoptotic cell and it was explained by Ballu et al (54) who found that GSE had a good protection against DNA damage in ischemia-reperfusion injury model as it inhibited oxidative damage to DNA as it blocks cell death signaling. It was also in line with Ye et al (55), who suggested GSE had a clear killing effect on the tumor cells without hurting the normal cells.

In conclusion, grape seeds extract was found to have a great beneficial effect in the biochemical and renal-cortical changes observed as a results of paracetamol overdose. Oxidative stress is one of the mechanisms by which paracetamol causes renal damage. Grape seeds extract, through its antioxidant properties may offer a promising natural and safe new trend for the prevention of paracetamol renal toxicity.

\section{References}

1. Sheen C, Dillon J, Bateman D et al. Paracetamol toxicity: epidemiology, prevention and costs to the health-care system. Month J Assoc Phys 2002; 95 (9): 609-619.

2. Lancaster EM, Hiatt JR, Zarrinpar A. Acetaminophen hepatotoxicity: an updated review. Arch Toxicol 2015; 89: 193-199.

3. Ucheya RE, Igweh JC. Histological changes in kidney structure following a long-term administration of paracetamol (acetaminophen) in pregnant Sprague-Dawley rats. Niger J Physiol Sci 2006; 21: 77-81.

4. Jones AF, Vale JA. Paracetamol poisoning and the kidney. J Clin Pharm Ther 1993; 18 (1): 5-8.
5. Soejarto DD, Fong HH, Tan GT et al. Ethnobotany/ethnopharmacology and mass bioprospecting: Issues on intellectual property and benefitsharing. J Ethnopharmacol 2005; 100 (1-2): 15-22.

6. Sarumathy KA. Protective effect of Caesalpiniasappan on acetaminophen induced nephrotoxicity and oxidative stress in male albino rats. J Pharmacol Toxicol 2011; 15 (2): 598-605.

7. Abdul RA, Gopalakrishnan G, Venkatesan $P$ et al. Isolation and identification of mosquito larvicidal compound from Abutilon indicum (Linn.). Sweet Parasitol Res 2008; 102 (5): 981-988.

8. Ghosh J, Das J, Manna P et al. Acetaminophen induced renal injury via oxidative stress and TNF- $\alpha$ production: therapeutic potential of arjunolic acid. Toxicology 2010; 268: 8-18.

9. Das J, Ghosh J, Manna P et al. Taurine protects acetaminophen-induced oxidative damage in mice kidney through APAP urinary excretion and CYP2E1 inactivation. Toxicology 2010; 269: 24-34.

10. Shi J, Yu J, Pohorly JE et al. Polyphenolics in grape seeds-biochemistry and functionality. J Med Food 2003; 6: 291-299.

11. Bagchi D, Sen CK, Ray SD et al. Molecular mechanisms of cardioprotection by a novel grape seed proanthocyanidin extract. Mutat Res 2003; 523: 87-97.

12. Saeed C, Ashtiyani 1, Houshang $\mathbf{N}$ et al. Grape Seed Extract for Reduction of Renal Disturbances Following Reperfusion in Rats. Iran J Kidney Dis 2013; 7: 28-35.

13. Mehrad H, Yousef D, Fataneh $\mathrm{H}$ et al. Effect of grape seed extract on renal ischemic reperfusion. J Anim Veter Adv 2012; 11 (14): 2529-2532.

14. Kuralay F, Akarca US, Ozutemiz AO et al. Possible role of glutathione in prevention of acetaminopheninduced hepatotoxicity enhanced by fish oil in male wistar rats. J Toxicol Environ Health Part A Toxicol Health 1998; 53: 223-229.

15. Buege J, Aust S. Microsomal lipid peroxidation. Meth Enzymol 1978; 52: 302-310.

16. Drury R, Wallington EA. Carleton histological techniques. New York: Oxford University Press; 1980: 279-313.

17. Côté A, da Silva R, Cuello AC. Current protocols for light microscopy immunocytochemistry. In: Cuello AC (Ed). Immunohistochemistry II: John Wiley \& Sons, Chichester; 1993: 147-168.

18. Bessems JG, VermeulenNP. Paracetamol (acetaminophen)-induced toxicity: molecular and biochemical mechanisms, analogues and protective approaches. Crit Rev Toxicol 2001; 31: 55-138.

19. Schnellman RG. Casarett and Doull's Toxicology: The Basic Science of Poisons. New York: McGraw-Hill Medical Publishing Division; 2001: 491-514.

20. Karakus E, Halici Z, Albayrak A, Polat B, Bayir Y, Kiki I, Cadirci E, Topcu A, Aksak S. Agomelatine: an antidepressant with new potent hepatoprotective effects on paracetamol-induced liver damage in rats. Hum Exp Toxicol 2013; 32: 846-857.

21. Palani S, Raja S, Praveen Kumar R, SoumyaJayakumar B, Senthil K. Therapeutic efficacy of Pimpinellatirupatiensis (Apiaceae) on acetaminophen induced nephrotoxicity and oxidative stress in male albino rats. Internat J Pharm Tech Research 2009; 1(3): 925 - 934.

22. Canayakin D, Bayir Y, Kilic N B, Sezen E K, Tarik H A, Betul F K, Sait M K, Halici. Paracetamol-induced nephrotoxicity and oxidative stress in rats: the protective role of Nigella sativa. Pharm Biol J 2016; 54: 2082-2091. 
23. Satirapoj B, Lohacit P, Ruamvang T. Therapeutic dose of acetaminophen with fatal hepatic necrosis and acute renal failure. J Med Assoc Thai 2009; 90 (6): 1244-1247.

24. Damera S, Raphael KL, Baird BC, Cheung AK, Greene T, Beddhu S. Serum alkaline phosphatase levels associate with elevated serum Creactive protein in chronic kidney disease. Kid Int 2011; 79 (2): 228-233.

25. Karadeniz A, Yildirim A, Simsek $\mathbf{N}$ et al. Spirulinaplatensis protects against gentamicin-induced nephrotoxicity in rats. Phytother Res 2008; 22: $1506-1510$.

26. Ajami M, Eghtesadi S, Pazoki-Toroudi H, Habibey R, Ebrahimi S A. Effect of Crocus sativus on gentamicin induced nephrotoxicity. Biol Res 2010; 43: 83-90.

27. Kehrer JP. Free radicals as mediators of tissue injury and disease. Crit Rev Toxicol 1993; 23: 21-48.

28. Draper HH, Hadley M. Malondialdehyde determination as index of lipid peroxidation. Meth Enzymol 1990; 186: 421-431.

29. Whidden MA, Kirichenko N, Halici Z, Erdos B, Foster TC, Tumer N. Lifelong caloric restriction preventsage-induced oxidative stress in the sympathoadrenalsystem of Fischer 344_brown Norway rats. Biochem Biophys Res Commun 2011; 408: 454-458.

30. Demirba S, Uysal B, Guven A, Cayci T, Ozler M, Ozcan A. Effects of medical ozone therapy on acetaminophen-induced nephrotoxicity in rats. Renal Failure 2010; 32: 493-499.

31. Linares MV, Belles M, Albina ML, Sirvent JJ, Sanchez DJ. Assessment of the pro-oxidant activity of uranium in kidney and testis of rats. Toxicol Lett 2006; 167: 152-161.

32. Newton J, Hoefle D, Gemborys M, Mugede G, Hoook J. Metabolism and excretion of glutathione conjugate of acetaminophen in the isolated rat kidney. J Pharmacol Exp Ther 1996; 237: 519-524.

33. Manov I, Hirsh M, Ianccu TC. Acetaminophen hepatotoxicity and mechanisms of its protection by N-acetylcysteine: a study of Hep 3B cells. Exp Toxicol Pathol 2003; 53: 489-500.

34. Trumper L, Coux G, Elías MM. Effect of acetaminophen on $\mathrm{Na}^{+}, \mathrm{K}+$ ATPase and alkaline phosphatase on plasma membranes of renal proximal tubules. Toxicol Appl Pharmacol.2000; 164: 143-148.

35. Ganga P, Ganesana R, harmalingama MD et al. Evaluation of Wound Healing Activity of Abutilon indicum Linn in Wister Albino Rats. Int J Biol Med Res 2011; 2 (4): 908-991.

36. Sanchez, C, Penarroja, M, Borras, $M$ et al. Bioaccumulation of metals and effects of a landfill in small mammals Part III: structural alterations. Environ Res 2009; 109: 960-967.

37. Trumper L, Monasterolo LA, Elias MM. Probenicid protects against in vivo acetaminophen induced nephrotoxicity in Male Wistar rats. Pharmacol 1998; 284: 606-610.

38. Tripathi S, Srivastav A. Cytoarchitectural alterations in kidney of Wistar rat after oral exposure to cadmium chloride. Tissue Cell 2011; 43: $131-136$.

39. Goligorsky M, Lieberthal W, Racusen L. Significance of Cadmium Intake and residues in terrestrial Small Mammals. Ecotoxicol Environ Safety 1993; 29: 101-112.
40. Prozialeck W, Lamar P, Lynch S. Cadmium alters the localization of $\mathrm{N}$-cadherin, E-cadherin and beta-catenin in the proximal tubule epithelium. Toxicol Appl Pharm 2006; 189: 180-195.

41. Mohamed SA, Elsharkawy SA. Histological study of early and late nephrotoxicity and endothelial cytotoxicity of ionic and non-ionic contrast media. Egypt J Anat 1995; 18: 115-132.

42. De Broe ME, Elseviers MM. Over-the-counter analgesic use. J Am Soc Nephrol 2009: 20 2098-2103.

43. Corina L, Pilar J, Ana S et al. Paracetamol-Induced Renal Tubular Injury: A Role for ER Stress. J Am Soc Nephrol 2004; 15 (2): 380-389.

44. Fouad AA, Yacoubi MT, El-Bidawy MH. Therapeutic potential of hemin in acetaminophen induced nephrotoxicity in rats. Envoiron Toxicol Pharmacol 2009; 27: 277-282.

45. Bagchi D, Bagchi M, Stohs SJ. Free radicals and grape seed proanthocyanidin extract: Importance in human health and disease prevention. Toxicology 2000; 148 (2-3): 187-197.

46. Li WG, Zhang XY, Wu YJ et al. Anti-inflammatory effect and mechanism of proanthocyanidins from grape seeds. Acta Pharmacol Sin 2001; 22 (12): 1117-1120.

47. Ray SD, Bagchi PM, Lim M, Bagchi SM, Gross SC, Kothari HG, Preuss SJ. Acute and long-term safety evaluation of a novel IH636 grape seed proanthocyanidin extract. Res Commun Mol Pathol Pharmacol 2001; 109: 165-197.

48. Tsang CC, Auger W, Muller A, Bornet JM, Ronanet A, Crozier PL. The absorption, metabolism and excretion of flavan-3-ols and procyanidins following the ingestion of a grape seed extract by rats. Brit $\mathrm{J}$ Nutr 2005; 94: 170-181.

49. Mohanasundari M, Sabesan M, Sethupathy S. Renoprotective effect of grape seed extract in ethylene glycol induced nephrotoxic mice. Indian J Exp Biol 2005; 43: 356-359.

50. El-Sayed ME, Mansour MA, Nady EM. Protective effects of red wine polyphenols and grape-seed proanthocyanidin extract on acetaminophen-induced liver injury. Internat J Pharm Sci Res 2014; 5: 9475-9492.

51. Gulsum O, Sukru U, Asim O et al. Protective Effect of the Grape Seed Proanthocyanidin Extract in a Rat Model of Contrast-Induced Nephropathy. Kidney Blood Press Res 2012; 35: 445-453.

52. Saeed C, Ashtiyani 1, Houshang $\mathbf{N}$ et al. Grape Seed Extract for Reduction of Renal Disturbances Following Reperfusion in Rats. Iran J Kidney Dis 2013; 7: 28-35.

53. Terra $\mathbf{X}$, Valls J, Vitrac $\mathbf{X}$ et al. Grape-seed procyanidins act as antiinflammatory agents in endotoxin-stimulated RAW 264.7 macrophages by inhibiting NFkB signaling pathway. J Agric Food Chem 2007; 55 : 4357-4365.

54. Balu M, Sangeetha $\mathbf{P}$, Murali G et al. Modulatory role of grape seed extract on age-related oxidative DNA damage in central nervous system of rats. Brain Res Bull 2006; 68: 469-473.

55. Ye X, Krohn RL, Liu W et al. The cytotoxic effects of a novel IH636 grape seed proanthocyanidin extract on cultured human cancer cells. Mol Cell Biochem 1999; 196: 99-108. 